\title{
Topics
}

\section{Long-Term Operation of the Energy Storage System for Lunar and Planetary Missions}

\author{
By Yoshitsugu SonE ${ }^{1,2)}$, Takeshi Hoshino ${ }^{1)}$ and Jun'ichiro KAWAGUCHI ${ }^{1)}$ \\ ${ }^{1)}$ Lunar and Planetary Exploration Program Group, Japan Aerospace Exploration Agency, Sagamihara, Japan \\ ${ }^{2}$ The Graduate University of Advanced Studies, Sagamihara, Japan
}

(Received July 17th, 2009)

\begin{abstract}
The Japan Aerospace Exploration Agency (JAXA) has been developing lithium-ion secondary cells for aerospace applications. Lithium-ion secondary cells were first used for the interplanetary spacecraft, HAYABUSA. For the long-term operations on the moon and interplanetary orbit, in-orbit performance of the lithium-ion battery demonstrated by HAYABUSA has been precisely examined. Furthermore, the regenerative fuel cell system is also one of the most important candidates to the future lunar and planetary missions where the higher energy density is required.
\end{abstract}

Key Words: Lunar Exploration, Space Technology, Electrical Power Subsystem

\section{Introduction}

Lithium-ion secondary cells/batteries have received significant attention because of their higher energy densities compared to $\mathrm{Ni}-\mathrm{Cd}, \mathrm{Ni}-\mathrm{MH}$ and $\mathrm{Ni}-\mathrm{H}_{2}$ batteries. In the field of space technology, a number of current efforts are focused on applying them in spacecraft ${ }^{1-17)}$.

One example is STENTOR, which attempted to demonstrate a SAFT 40 Ah lithium-ion battery system in a geo-stationary orbit $^{1-11)}$. The European piggy-back satellite 'PROBA' uses lithium-ion batteries produced by AEA using off-the-shelf lithium-ion cells from SONY ${ }^{2}$. The same technology was also applied to European planetary missions such as the satellite 'Rosetta' and the 'Mars-Express'"2).

The Japan Aerospace Exploration Agency (JAXA) has been developing lithium-ion secondary cells for aerospace applications $^{5-11)}$. For scientific missions like interplanetary missions, lithium-ion secondary batteries have already been applied. One example is HAYABUSA. This spacecraft used 13.2 Ah lithium-ion secondary cells. To realize maximum performance of the battery for long flight operation, the state-of-charge (SOC) of the battery was maintained at ca. $65 \%$ during storage in case it is required for contingency operations. The battery was used for the earth swing-by operation, touch-down operation on ITOKAWA, and finally used to close the lid of the sample container. Based on the above experience, JAXA is going to apply lithium-ion secondary battery for planetary missions like PLANET-C and MMO.

Lithium-ion secondary cells are much attractive for the lunar and planetary mission since the energy density realized by the cell is $100-160 \mathrm{Wh} / \mathrm{kg}$. It is about twice or three times higher than the conventional $\mathrm{Ni}-\mathrm{Cd}, \mathrm{Ni}-\mathrm{MH}$ and $\mathrm{Ni}-\mathrm{H}_{2}$. However, higher energy density exceeding current lithium-ion secondary cells start to be requested for the future lunar and planetary mission. To meet these various requests to the energy

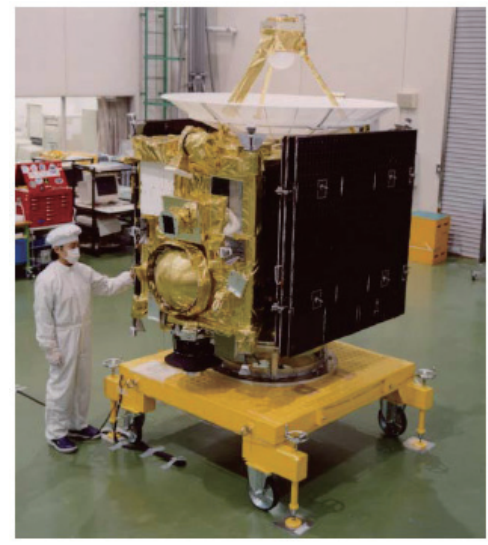

Fig. 1. The interplanetary spacecraft HAYABUSA.

storage devices for the scientific missions, the in-orbit data of the lithium-ion secondary battery obtained from HAYABUSA has been precisely examined. Furthermore, the applicability of the regenerative fuel cell system is also under discussion. In this paper, the current status of the data analysis of the HAYABUSA battery and the current status of the research for the regenerative fuel cell is discussed.

\section{Storage of the Lithium-Ion Secondary Battery in Space}

In the case of interplanetary missions especially, a light-weight and compact battery is critical, and the application of lithium-ion cells has been considered ${ }^{9-11)}$.

It is very important for the future lunar and planetary missions to confirm the long-term operability of the energy storage devices with high energy density. In the case of the lithium-ion secondary cells, energy is stored at higher voltage comparing to the conventional devices like Ni-Cd, Ni-MH and $\mathrm{Ni}-\mathrm{H}_{2}$ cells. The high voltage causes the decomposition of the electrolytic solution and the increase in the impedance of 

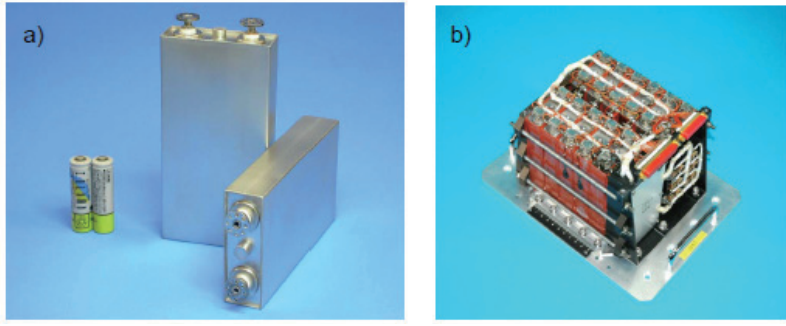

Fig. 2. The lithium-ion secondary cells (a), and battery (b). The lithium-ion secondary cells are compared to AA-cells.

the cell. Furthermore, the decomposition also consumes lithium-ions stored inside the electrode, which induces the decrease in the capacity to be discharged.

In order to realize the future operability of the lithium-ion secondary cells for lunar and planetary missions, in-orbit performance of the HAYABUSA battery is under investigation. Fig. 1 shows the spacecraft HAYABUSA. It was launched on May 9, 2003. This spacecraft used 13.2 Ah lithium-ion secondary battery/cells shown in Fig. 2. The basic specifications of the lithium-ion secondary cells were listed in Table 1.

In general, the storage of the lithium-ion cells at a high state-of-charge (SOC) accelerates the decay of the cell performance. The high SOC enhances the formation of the solid electrolyte interface (SEI) film which is formed on the negative electrode. Since the formation of SEI consumes lithium ions inside the negative electrode, the capacity of the cell will fade. Furthermore, SEI has a lower conductivity than other materials used in the cell; therefore the cell impedance is increased by its formation.

Considering the performance of the HAYABUSA battery, for which a high depth-of-discharge (DOD) with a high discharge current is required after a long-term storage, the best method to maintain cell performance is storage at a lower temperature with low SOC. However, in the case of a contingency, the battery has to be discharged appropriately. Thus, it was decided that the temperature of the battery should be maintained at about 5 degrees $\mathrm{C}$, and that the SOC level of the battery should be kept around $65 \%$.

Fig. 3 shows the trend of voltage during the flight operation on the way to ITOKAWA. The voltage of the battery was

Table 1. Specifications of the lithium-ion secondary cell in HAYABUSA.

1) The rated capacity assumed charging at $6.60 \mathrm{~A}(0.5 \mathrm{C})$ and discharging at $2.64 \mathrm{~A}(0.2 \mathrm{C})$ at 20 degrees $\mathrm{C}$.

\begin{tabular}{|c|c|c|}
\hline \multicolumn{2}{|c|}{ Rated Capacity $^{1)}$} & $13.2 \mathrm{Ah}$ \\
\hline Discharge Voltage (Agerage) & ${ }^{1)}$ & $3.6 \mathrm{~V}$ \\
\hline \multirow{3}{*}{ Size } & Width & $69.3 \mathrm{~mm}$ \\
\cline { 2 - 3 } & Height & $132 \mathrm{~mm}$ \\
\cline { 2 - 3 } & Thickness & $24.4 \mathrm{~mm}$ \\
\hline Electrode Material & Positive & LiCoO \\
\cline { 2 - 3 } & Negative & Graphite \\
\hline \multicolumn{2}{|c|}{ Weight } & $<570 \mathrm{~g}$ \\
\hline \multicolumn{2}{|c|}{ Energy Density / mass } & $>85 \mathrm{Wh} / \mathrm{kg}$ \\
\hline \multicolumn{2}{|c|}{ Energy Density / volume } & $>215 \mathrm{Wh} / \mathrm{L}$ \\
\hline
\end{tabular}

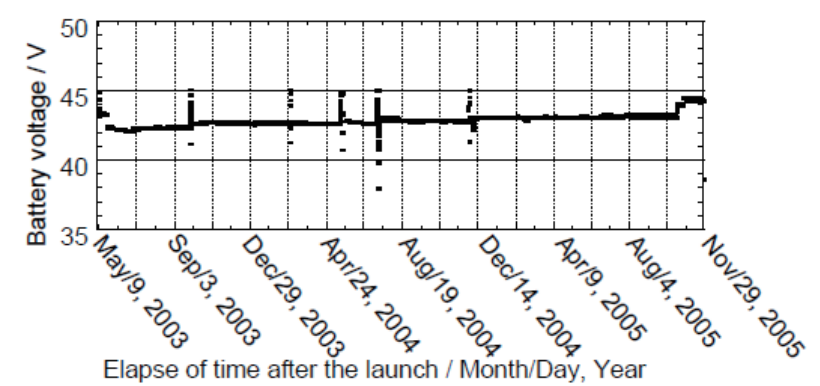

Fig. 3. Trend of the battery voltage in HAYABUSA flight.

not increased to the fully charged condition, and increased stepwise as shown in Fig. 3.

During the storage operation, the voltage in each cell is monitored, and this monitoring discharges the battery. The discharged capacity must be recovered by a slight charge up to around $65 \%$ SOC once a week. The temperature of the battery was controlled at 0 degrees $\mathrm{C}$. However, the slight temperature variation inside the battery and differences in performance of the monitoring circuit for each cell resulted in different SOC levels among the battery cells. For compensating the SOC levels, we charged the battery using a balance circuit which by-passes the current when the cell voltage reaches $4.1 \mathrm{~V}$. By spending time, the SOC level of each cell reaches the same level stepwise. After being charged completely, the battery was discharged to ca. $50 \%$ SOC using a heater-resistance of the spacecraft. The battery was then charged again to $65 \%$ to be ready for any contingency operation. In order to decide the voltage to be re-charged, ground test cells were used. The test cells were stored with the same SOC level at 0 degrees $\mathrm{C}$ as in space. When the balance operation was started, the ground test cells were also charged. By measuring the capacity of the cells, the voltage which realized the $65 \%$ SOC was confirmed. Based on the information, the in-orbit battery was charged again. The charge current for this operation was $500 \mathrm{~mA}$. The resistance of the heater used for the discharge was about 8 ohms. This operation was repeated every four months.

Furthermore, in order to conduct a precise simulation of the flight battery, we decided to measure the capacity of the battery in space, and compared it to that obtained from the ground tests. After the capacity measurement in space, the ground-test battery was also charged and discharged under the same conditions in orbit, so that we could compare the flight data with the ground test results.

On November 20 and 26 in 2005, HAYABUSA touched down on ITOKAWA, and, in doing so, it is likely that surface material from ITOKAWA entered the sample container.

When HAYABUSA attempted to leave the asteroid, the attitude control of the spacecraft malfunctioned and HAYABUSA could not be contacted for seven weeks. When communication with HAYABUSA was re-established, the telemetry data from the spacecraft revealed that four of the 11 series-connected cells had over-discharged during the malfunction.

It was also found that the lid of the asteroid sample container was still open. Before the sample from 


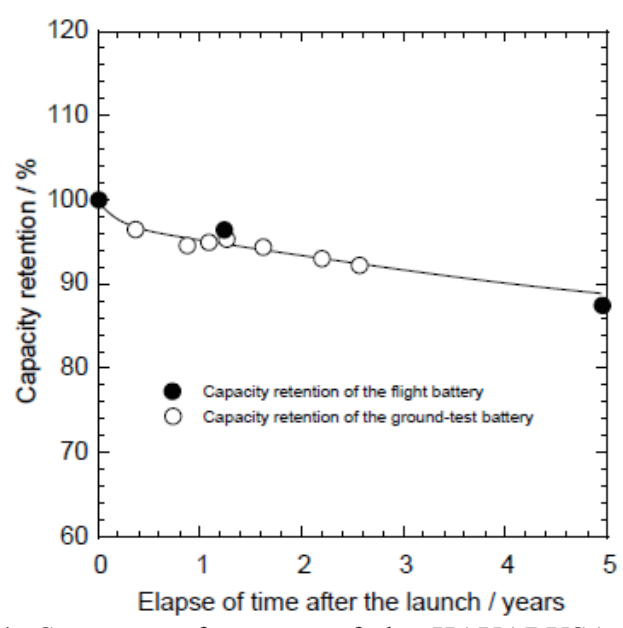

Fig. 4. Storage performance of the HAYABUSA battery. This figure was reported in the reference 8).

ITOKAWA could be returned to Earth, the lid had to be closed, the sample container had to be inserted into the Earth re-entry capsule, and the capsule had to be latched and sealed. All of these actions required power from the battery.

The seven healthy battery cells were then slowly charged at minimum current using current leaked from the charge bypass circuit. Ground tests and simulations were conducted using similarly-built and intentionally short-circuited cells to evaluate the operational safety of this procedure. After the safety of the lithium-ion secondary cells was confirmed, the lid of the sample container could be closed. The asteroid sample was then transferred into the Earth re-entry capsule, and latching and sealing of capsule was completed successfully using power from the over-discharged lithium-ion secondary battery.

The discharged current during this operation was only $1 \mathrm{~A}$ for less than 1 minute, and the discharge was repeated four times. Thus, the total discharged capacity was quite small. After this operation, the fully charged 7 cells were remained in space. The battery has the monitoring circuits. The circuit monitors the voltage of each cell. The circuits have high impedance, but current was leaked from each cell through the circuit. The leak current was about $1 \mathrm{~mA}$.

By spending about 1.5 years, the cells lost their capacity. Based on the information, the capacity which was finally realized after the five years storage in space was calculated. Fig. 4 shows the trend of the storage performance of the lithium-ion secondary cells. The capacity trend obtained from the ground test cells was also shown in Fig. 4. Both trends show good agreement. The result confirmed that the storage performance of the lithium-ion secondary battery in space is precisely predictable using a ground-tests battery.

Today, lunar missions receive much attention, and the energy storage system for the exploration must be designed. One candidate is a lithium-ion secondary battery. As mentioned above, long-term operability of the lithium-ion secondary cells are confirmed today. Furthermore, the energy density of the lithium-ion secondary cell is increasing today. One problem is the thermal control of the battery. In the case of HAYABUSA, the temperature of the battery was maintained at around 0 degrees C. However, the temperature on the surface of the moon differs quite a lot between day and night. Moreover, it is very hard to release the heat of the spacecraft/probe to the outside because one side of the spacecraft/probe must face to the lunar surface. If the battery requests the same conventional temperature range for the operation, adequate thermal control becomes difficult due to the environmental conditions around the probe. In order to solve the problem, the cell performance at higher and lower temperature than the conventional applications is under testing.

\section{Applicability of Fuel Cell System}

Energy density which can be realized by the lithium-ion secondary cell is approaching to $200 \mathrm{Wh} / \mathrm{kg}$. However, some innovative technological breakthrough must be requested to realize the higher energy density than the current lithium-ion technology.

Another candidate of the energy storage system which can realize the high energy density is fuel cell (FC) and regenerative fuel cell (RFC) system.

Fuel cells have been applied in the field of space engineering to spacecraft since the 1960s. A fuel cell produces water as a by-product of generating electricity, making it attractive for manned operations in a closed environment. Furthermore, the fuel cell generates energy using hydrogen and oxygen, both of which have high energy density. This important potential continues to make fuel cells advantageous for application to large spacecraft with short-term missions.

The first practical application of fuel cell was started in space for GEMINI project, and the first fuel cell to travel in space was the polymer electrolyte fuel cell (PEFC). However, the membrane for the fuel cell was polystyrene, not perfluoro-membrane, and high power supply, which is commonly achievable today, was not realized. When the APOLLO and Space Shuttle missions started, PEFC was replaced by an alkaline fuel cell system. Water produced with the electricity by fuel cells is very attractive to space programs. However, there was another reason that the fuel cells were applied to the space programs. The energy density of the fuel cell used to the Space Shuttle missions is over $1,000 \mathrm{Wh} / \mathrm{kg}$. In order to obtain the energy generating system with light weight, fuel cell is one of the most attractive systems. Alkaline fuel cell systems applied to the Space Shuttle was very reliable, while the cost to maintain the performance of the system was unsatisfied to deliver the same technology to the widely usable ground facilities.

After decades, the research and development of PEFC is gathering much attention again due to its applicability to ground facilities. These situations also stimulate the consideration of the applicability of PEFC to aerospace programs $^{13-14)}$.

One example is the stratospheric platform project ${ }^{12-15)}$. A lightweight, long-duration generating system is required to maintain the altitude and position of an aircraft or airships in the stratosphere. Lighter-weight, higher-output electrical 


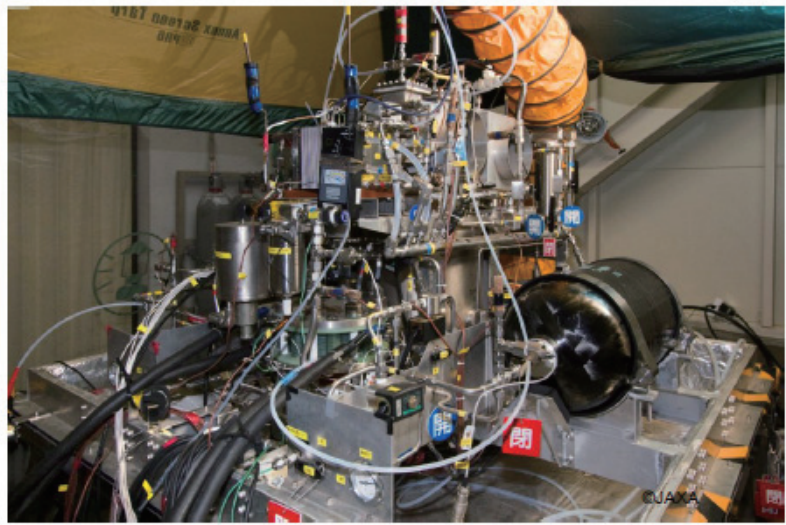

Fig. 5. $1 \mathrm{~kW}$ regenerative fuel cell, testing for the airship.

power systems will be requested in near future ${ }^{13-17)}$.

In Japan, RFC was first designed to be applied to the stratospheric platform, and JAXA have already started the advanced design of the RFC. The $1 \mathrm{~kW}$-class RFC shown in Fig. 5 was prepared to confirm the system design concept of RFC, and the performance of the system has been tested by simulating environmental conditions in the stratospheric area. The target of the RFC for stratospheric platform is to realize $450 \mathrm{Wh} / \mathrm{kg}$ when the $15 \mathrm{~kW}$-class RFC is prepared.

Fig. 6 shows the concept design model of $100 \mathrm{~W}$-class regenerative-fuel-cell system. It was prepared by the 'Fuel Cell Team of JAXA' to demonstrate the performance using International Space Station. In order to prepare the compact RFC system, $12 \mathrm{~V} / 10$ A-class fuel cell was combined with $100 \mathrm{~W}$-class electrolyzer. In this system, gas/water separator which is operative under the low gravitational condition was installed, and continuous operation in the closed environment was realized.

Conventionally, RFC was designed by the combination of fuel cell and electrolyzer. However, both units use the electrochemistry by the reaction between hydrogen and oxygen. Hydrogen and oxygen is combined to produce water for fuel cell reaction, and water is decomposed to hydrogen and oxygen for electrolysis reaction. Theoretically, one unit can be used for the reversible reaction which generates both electricity and hydrogen/oxygen. This concept is so-called unitized regenerative fuel cell (URFC). We expect that the URFC system is final design target of the regenerative fuel cell system in future.

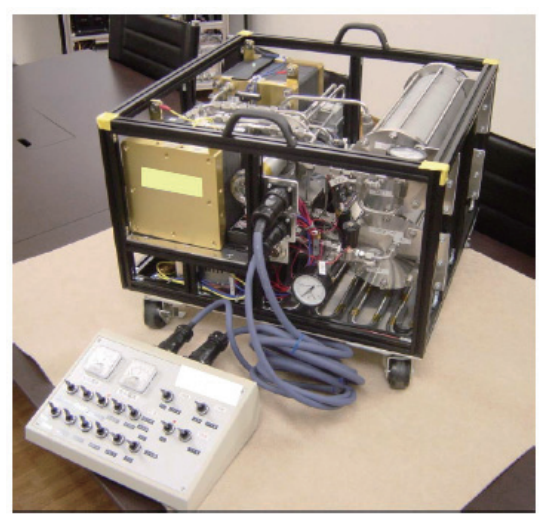

Fig. 6. $100 \mathrm{~W}$-class regenerative fuel cell system.
In order to accomplish these technologies, we need to understand the capability of all essential units like fuel cell, gas/water separation technique, and electrolyzer.

Basic operability of the fuel cell under closed environment has also been demonstrated by JAXA. We prepared $100 \mathrm{~W}$ and $1 \mathrm{~kW}$-class polymer-electrolyte fuel cell stacks ${ }^{16-17)}$. Our previous study using these stacks revealed that the polymer-electrolyte fuel cells could be operated without humidification using a combination of pure hydrogen and oxygen. Hydrogen and oxygen supplied from opposite directions to realize the counter flow of the gases inside the fuel cell could generate electricity continuously. This is possible even when the hydrogen outlet port is dead-ended and oxygen gas is recycled to increase consumption of the reactants.

We then designed a fuel cell stack using a catalyst with a larger effective surface area and a dehydrator that could remove water from the reactant gas using wicking material. We incorporated these elements with a gas-circulation pump and used this fuel cell system model to generate electricity using pure hydrogen and oxygen with no extra humidification $^{15-17)}$.

The important point for the operation here was the direction of gas flow. Through our experiments, the fuel cell performance degraded immediately if the gases were supplied in the same direction to realize the concurrent flow across the MEA without humidification. The amount of water produced inside the fuel cell can be low in the upper part and high in the lower part of the gas stream. This gradient accelerated the heterogeneous distribution of water in the cell.

In order to obtain stable performance of the fuel cell, water must be homogeneously distributed, so we supplied hydrogen and oxygen from opposite directions across the membrane electrolyte assembly (MEA). In this case, the water produced on the cathode side is carried to the lower stream of oxygen and migrates to the anode side. This migrating water humidifies the counter flow of dry hydrogen across the MEA and carries the humidity to its lower stream. Furthermore, the humidity carried by the hydrogen stream migrates through the MEA in the upper stream of cathode gas where the membrane is rather dry. As a result, we can realize a favorable distribution of water inside the fuel cell.

In this case, the gas-flow channel was serpentine, but we observed the same effect of gas flow directions even in a inter-digit-gas-flow-field.

Cathode and anode gases were fed from opposite directions to realize the counter flow without humidification. During the whole operation, the stack was continuously operated at an average cell voltage of $0.75 \mathrm{~V}$ for $60 \mathrm{~A}\left(0.37 \mathrm{~A} / \mathrm{cm}^{2}\right)$, and we could successfully demonstrate stable fuel cell performance for hours without humidification.

Our test also demonstrated the PEFC operation of closed gas conditions. All reactants must be carried inside the vehicle for space applications. Ideally, then, reactant gases must be fully consumed with no exhaust. This environmental restriction caused us to test the fuel cell performance under closed conditions, and we tried to circulate 


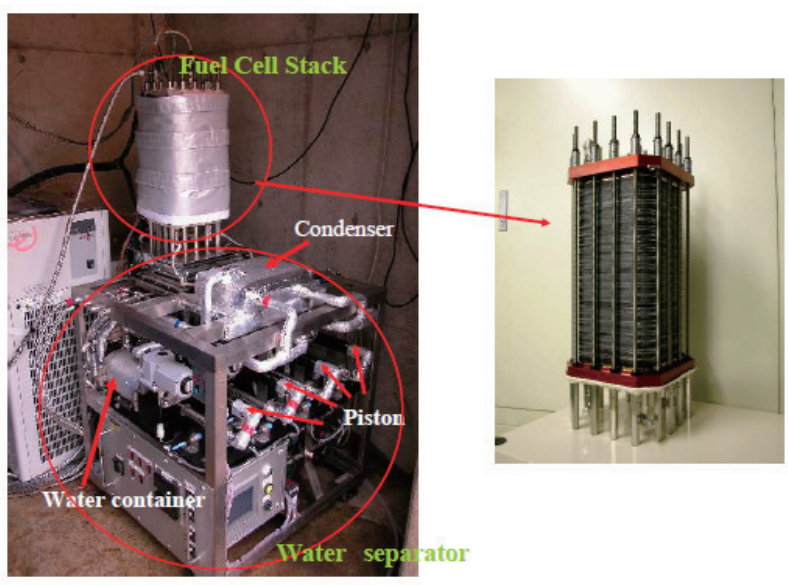

Fig. 7. $1 \mathrm{~kW}$-class fuel cell demonstration model.

hydrogen and oxygen.

The water produced by the use of oxygen must constantly be removed from the catalyst layer of the MEA. We therefore installed a dehydrator along the gas recycling line together with a gas circulation pump. The dehydrator can remove water by condensation. The removed water was wicked up and reapplied to humidify the fuel cell by controlling the temperature of the dehydrator. Gas circulation also plays an important role in inhibiting flooding on the cathode side. In this operation, the gas circulation rate was four times greater than the theoretically required mass. The appropriate circulation rate resulted in constant fuel cell performance.

Ideally, if the hydrogen outlet at the anode were to be closed, the simplest system could be realized. To do this, we must prevent condensation and accumulation of un-vaporized water in hydrogen with subsequent flooding on the anode side. In our previous report, we demonstrated that the hydrogen outlet port could be dead-ended. However, we installed the gas circulation system and dehydrator along the hydrogen gas flow line as well as the oxygen line to maintain a continued stable performance under the microgravity conditions of the system. In our previous system, we dead-ended the hydrogen outlet port, so that the slow hydrogen stream might maintain the humidity inside the fuel cell. However, the results of continuous operation of the current system confirmed that stable performance of the PEFC system could be maintained by the hydrogen gas circulation even without external humidification.

The purity of reactant gas is also important for gas circulation or closed gas operation. When we used low purity gases, we observed degraded fuel cell performance. Impurities such as nitrogen inside the fuel cell might also gradually decrease performance. Specifically, we used 99.99999\% pure hydrogen and $99.999 \%$ pure oxygen for continuous operation. Even though we use such pure gases, we need to purge at regular time intervals to operate a fuel cell in a closed environment. In our system, the water that accumulated inside the dehydrator cylinder was ejected by the movement of the piston at regular time intervals. The gas inside the cylinder was also ejected by the piston movement, which plays the same role as the purge system for the

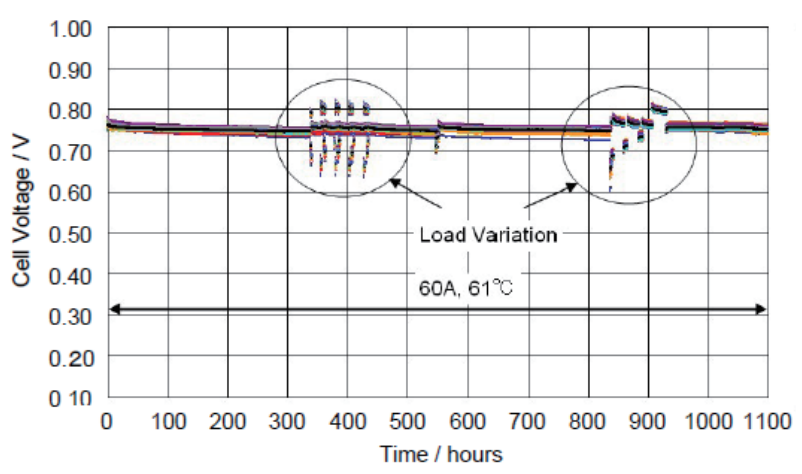

Fig. 8. Continuous operation of a $1 \mathrm{~kW}$-class fuel cell system. The cell voltage of 18 cells were shown together. Both hydrogen and oxygen were circulated. This figure was already reported in reference 13).

impurities. The piston movement interval is automatically controlled by the sequencer installed in the system.

Based on these prototype designs, we prepared a fuel cell system that can be operated automatically in a closed environment shown in Fig. 7. The results shown here also demonstrated that automatic operation of the dehydrator facilitates constant operation of our system.

In the system, water is trapped by the wicking material installed on the cylinder so that the water can be separated from gaseous materials even under micro-gravity conditions. The amount of water that will be generated is calculated using the sequence controller, and the extracted water is ejected automatically using the piston attached to the cylinder. Both oxygen and hydrogen are circulated to minimize the amount of exhaust materials. We did not install a humidifier in this system. The counter flow of high purity hydrogen and oxygen resulted in self-humidification of the system with no degradation in performance.

Fig. 8 shows 1,100 hours continuous operation of the fuel cell. Although we varied the load current between 30 and 150 A simulating the Space Shuttle Operation, we observed no drastic degradation of the generating voltage of the PEFC stack.

Fig. 9 displays the I-V performance of the PEFC stack after continuous operation of the fuel cell system for 1,100 hours. We observed almost the same I-V characteristics for the stack even after the extended operation, verifying the system concept and the subsystem component function in our system. In a Space Shuttle, the operation period for one flight is about 250 hours (10 days), and the maintenance interval for its alkaline fuel cell is every 2,500 hours. Furthermore, in the case of the lunar applications, the night continues for over 350 hours. If the spacecraft/probe tries to survive over three nights, fuel cell must work for more than 1,000 hours. Our test results demonstrated the applicability of the PEFC system to the space programs like Space Shuttle and lunar missions.

For the above measurement, wick was used to trap the product water. We also developed the gas/water separation pump which is applicable under microgravity conditions. In order to recycle the reactant gas, the gas must be pressurized. 


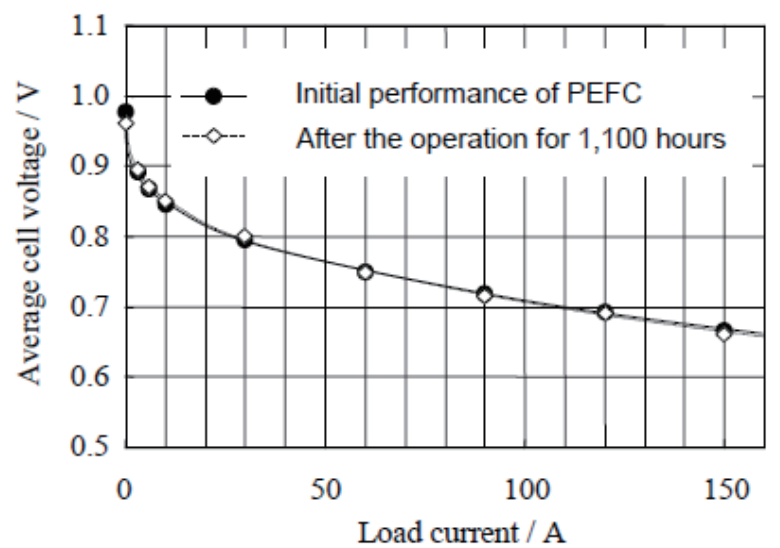

Fig. 9. I-V characteristics of an eighteen-cell stack PEFC. The fuel cell was operated without humidification for 1,100 hours. This figure was already reported in reference 13).

When it is pressurized, water is trapped by using the centrifuge force. The performance of the pump has already been demonstrated, and we confirmed an adequate pressure was produced by the device to drive the fuel cell reaction continuously.

Currently, the understanding of the electrolysis technology is also proceeding. We expect that these research and development will realize the application of the RFC system to lunar exploration mission in future.

\section{Summery}

The Japan Aerospace Exploration Agency (JAXA) has been developing lithium-ion secondary cells for aerospace applications. For scientific missions like interplanetary missions, lithium-ion secondary batteries have already been applied. The Japanese spacecraft, HAYABUSA, was launched on May 9, 2003 and spent more than 2.5 years approaching the asteroid ITOKAWA. This spacecraft used 13.2 Ah lithium-ion secondary cells. The trend of the storage performance of the lithium-ion secondary cells was compared to that obtained from the ground test cells. Both trends showed good agreement. The result confirmed that the storage performance of the lithium-ion secondary battery in space is precisely predictable using a ground-tests battery.

Another candidate of the energy storage system for the lunar mission is regenerative fuel cell (RFC). RFC was first designed to be applied to the stratospheric platform, and JAXA have already started conceptual research of the advanced design of the RFC.

\section{Acknowledgments}

This research of the fuel cell system for the closed environment was partially supported by the New Energy and Industrial Technology Development Organization (NEDO) as a grant number $04 \mathrm{~A} 40008$.

\section{References}

1) Planchat, JP. and Borthomieu, Y.: VES $100 \mathrm{~S}$ Li-Ion BOL Qualification, Proc. $6^{\text {th }}$ Euro. Space Power Conf., (2002), pp. 483-487.

2) Spurrett, R., Thwaite, C., Slimm, M. and Lizius, D.: Lihium-Ion Batteries for Space, Proc. $6^{\text {th }}$ Euro. Space Power Conf., 2002, pp. 477-482.

3) Imamura, N., Inoue, T., Yoshida, H., Mizutani, M. and Goto, M.: Long Life Large Scale Lithium-Ion Cell for Space Applications, Proc. 40 ${ }^{\text {th }}$ Power Source Conf., (2002), pp. 10-13.

4) Inoue, T., Imamura, N., Yoshida, H., Komada, K., Mizutani, M. and Goto, M.: Calendar and Cycle Life Test Results of $100 \mathrm{Ah}$ Lithium Ion Cells for Space Applications, Proc. $19^{\text {th }}$ AIAA Int. Communication Satellite Systems Conf., (2001), pp. 17-20.

5) Sone, Y., Liu, X., Inoue, T., Wang, X., Kuwajima, S.: Cycle-Life Evaluation of the 30 Ah Prismatic Li-Ion Secondary Cells for Low Earth Orbit Satellite, Electrochem. 71, (2003), pp. 542-548.

6) Yamada, C., Wang, X., Naito, H., Sone, Y., Segami, G., Uno, M. and Kuwajima, S.: Update on Development of Lithium-ion Cells for Space Applications at JAXA, 2004 NASA Aerospace Battery Workshop, Huntsville, Alabama, USA, (2004).

7) Wang, X., Sone, Y. and Kuwajima, S.: In-Situ Investigation on the Volume Change of Lithium-Ion Cell with Charging and Discharging: An Understanding for Satellite Power Applications, J. Electrochem. Soc. 151, (2004), pp. A273-A280.

8) Wang, X., Sone, Y. and Kuwajima, S.: Effect of operation conditions on simulated low-earth orbit cycle-life testing of commercial lithium-ion polymer cells, J. Power Sources, 142, (2005), pp. 313-322.

9) Sone, Y., Ooto, H., Yamamoto, M., Eguro, T., Sakai, S., Yoshida, T., Uno, M., Hirose, K., Tajima, M. and Kawaguchi, J.: The Performance of the Lithium-ion Secondary Cells under Micro-Gravity Conditions -In-Orbit Operation of the Interplanetary Spacecraft 'HAYABUSA', Electrochem., 75, (2007), pp. 518-522.

10) Sone, Y., Ooto, H., Eguro, T., Yoshida, T., Kubota, M., Yoshida, H., Yamamoto, M., Ogawa, K., Takeda, Y., Uno, M., Hirose, K., Tajima, M. and Kawaguchi, J.: Charge and Discharge Performance of Over-Discharged Lithium-ion Secondary Battery-Lessons Learned from the Operation of the Interplanetary Spacecraft HAYABUSA, Electrochem., 75, (2007), pp. 950-957.

11) Sone, Y., Ooto, H., Yamamoto, M., Eguro, T., Sakai, S., Yoshida, T., Takahashi, K., Uno, M., Hirose, K., Tajima, M. and Kawaguchi, J.: Storage of a lithium-ion secondary battery under micro-gravity conditions, J. Power Sources, 181, (2007), pp. 149-154.

12) Sone, Y., Ooto, H., Eguro, T., Yoshida, T., Kubota, M., Yoshida, H., Yamamoto, M. and Kawaguchi, J.: In-orbit Storage of the Lithium-ion Secondary Cells -The Operation of the Interplanetary Spacecraft 'HAYABUSA', $76^{\text {th }}$ Electrochem. Soc. $J,(2009), 3022$.

13) Loyselle, P. L., Maloney, T. M. and Cathey, Jr. H. M.: Design, Fabrication, and Testing of a $10 \mathrm{Kw}-\mathrm{Hr}$ Pem Fuel Cell Power System for High-Altitude Balloon Applications, The $34^{\text {th }}$ IECEC, (1999), Paper No. 1999-01-2588.

14) Naito, H., Eguchi, K., Hoshino, T. and Okaya, S.: Design Concept and Analysis of Solar Power Subsystem for SPF Airship Operations, AIAA, (1999), Paper No. 99-3913.

15) Sone, Y., Ueno, M. and Kuwajima, S.: Stable Performance of a Polymer Electrolyte Fuel Cell System in a Closed Environment without External Humidification, Electrochem., 74, (2006), pp. 768-773.

16) Sone, Y., Ueno, M. and Kuwajima, S.: Fuel Cells for Aerospace Applications and its Current Development, Electrochem., 70, (2002), pp. 705-710. (in Japanese)

17) Sone, Y., Ueno, M. and Kuwajima, S.: One kilowatt-class fuel cell system for the aerospace applications in a micro-gravitational and closed environment, J. Power Sources, 157, (2006), pp. 886-892. 